\title{
Preparation of Oligodimethylsiloxane-grafted Poly(amide-imide) Membrane and Its Separation Properties of Aqueous Organic Liquid Mixtures by Pervaporation
}

\author{
Masaji AкIмото, Eiichi AkIYAma, ${ }^{*}$ and Yu NAGASE ${ }^{\dagger}$ \\ Department of Applied Chemistry, Graduate School of Engineering, Tokai University, \\ 1117 Kitakaname, Hiratsuka 259-1292, Japan \\ *Technology Research Center, Ebara Research Co., Ltd., \\ 4-2-1 Honfujisawa, Fujisawa 251-8502, Japan
}

(Received February 16, 2004; Accepted May 17, 2004; Published August 15, 2004)

\begin{abstract}
In order to develop a durable membrane material for the separation of several organic liquids from their aqueous solutions by using pervaporation technique, oligodimethylsiloxane-grafted aromatic poly(amide-imide) copolymer was prepared by oligomer-polymer reaction. Poly(amide-imide) was reacted with NaH in DMSO to produce polyanion at the N-position of the amide group, followed by the reaction with chloromethylphenyl-terminated oligodimethylsiloxane (ODMS) to obtain the desired graft copolymer. By this oligomer-polymer reaction, ODMS chains with the average degree of polymerization of 13 or 19 were substituted on $19-85 \mathrm{~mol} \%$ of the amide group, where the degree of substitution was controlled to some extent by changing the mole ratio of $\mathrm{NaH}$ and the amide group. The obtained copolymers were soluble in aprotic polar solvents such as DMSO and NMP, and insoluble in the ordinary organic solvents such as alcohol, acetone, THF, benzene, chloroform and dichloromethane. The copolymer membranes were easily prepared by the solvent-casting method from their NMP solutions. The obtained graft copolymer with high ODMS content exhibited the stable and selective permeation of organic solvents, such as alcohol, acetone, THF and dichloromethane, from their dilute aqueous solutions. For example, $0.8 \mathrm{wt} \%$ aqueous dichloromethane solution was concentrated to $72.9 \mathrm{wt} \%$, where the separation factor $(\alpha)$ exceeded 334 with a flux of $0.99 \mathrm{~kg} \mathrm{~m}^{-2} \mathrm{~h}^{-1}$.

[DOI 10.1295/polymj.36.587]

KEY WORDS Poly(amide-imide) / Oligodimethylsiloxane / Graft Copolymer / Polymer Reaction / Pervaporation / Separation Membrane /
\end{abstract}

Recently, the pervaporation (PV) technique with a polymer membrane has been focused in much attention for separations of mixtures of several organic liquids and water. In particular, since it is possible to remove organic components from aqueous organic liquid solutions, PV technique is expected to be applied to a removal of organic components from waste fluid. For this purpose, it is more important that the membrane exhibits the organic-permselectivity in the permeation of mixtures of organic liquids and water, and the durability against several organic solvents. A cross-linked polydimethylsiloxane (PDMS) membrane or PDMS-containing copolymer membrane has been known to show a selective permeation of organic liquids in the pervaporation of aqueous organic solutions. ${ }^{1-3}$ We have also attempted to utilize the properties of a PDMS membrane which exhibited a high permeability of the organic component. For PV materials possessing the mechanical strength and the durability, the syntheses of siloxane-grafted copolymers have been studied, the main chain of which consisted of several aromatic polymers. ${ }^{4-10}$ In our previous work, it was found that polyimide/oligodi- methylsiloxane (PI/ODMS) graft copolymer membrane exhibited the high organic permselectivity in aqueous organic liquid solutions, such as acetone, THF chloroform and dichloromethane with a stable PV permeation. ${ }^{10}$ However, PI/ODMS graft copolymer must be prepared by casting in poly(amic acid) stage, followed by thermal imidation. In other words, this membrane possessed the excellent separation property but less processability due to the chemical structure of backbone component.

In this study, a novel membrane material has been investigated, which possesses the practical properties of permselectivity in PV, durability and processability. The main purpose of this work is to introduce poly(amide-imide) (PAI) into ODMS-grafted copolymer as a backbone component instead of polyimide, which would increase the solubility. PAI is soluble in some solvents such as aprotic polar solvents to be easily prepared a membrane by solvent-casting method, and insoluble in the other organic solvents to be durable to separating organic components. In this paper, we described the synthesis of poly(amide-imide) substituted with oligodimethylsiloxane chains at the

${ }^{\dagger}$ To whom correspondence should be addressed (E-mail: yunagase@keyaki.cc.u-tokai.ac.jp). 
$\mathrm{N}$-position of amide groups, which derived from a oligomer-polymer reaction, and the separation characteristics of the obtained membrane were evaluated by PV experiments.

\section{EXPERIMENTAL}

\section{Materials}

Trimethylsilanol was purchased from Shin-Etsu Chemical Co., Ltd., and hexamethylcyclotrisiloxane and dimethylchlorosilane were provided gratis by Chisso Corp. All the silicone-containing compounds were used without further purification. Trimellitic anhydride and 4,4'-diaminodiphenylmethane were purified by sublimation and recrystallization, respectively, just before use. Tetrahydrofuran (THF) and toluene were distilled over sodium to remove the small amount of water. Anhydrous 1-methyl-2-pyrrolidinone (NMP) and dimethylsulfoxide (DMSO) were purchased from Aldrich Chemical Co., Ltd.

\section{Synthesis of Hydrosilyl-terminated ODMS (H-ODMS)}

A solution of trimethylsilanol $(4.07 \mathrm{~g}, 45.2 \mathrm{mmol})$ in $100 \mathrm{~mL}$ of dry THF was prepared under an argon atmosphere, and $28.1 \mathrm{~mL}$ of $1.6 \mathrm{M}$ hexane solution of butyllithium was added to this solution at $0{ }^{\circ} \mathrm{C}$. After stirring for $30 \mathrm{~min}$, hexamethylcyclotrisiloxane $\left(\mathrm{D}_{3}, 50.0 \mathrm{~g}, 226 \mathrm{mmol}\right)$ dissolved in $150 \mathrm{~mL}$ of dry THF was added, and the reaction mixture was stirred at room temperature for $5 \mathrm{~h}$. Then, $10.0 \mathrm{~mL}$ of dimethylchlorosilane was added in order to terminate the polymerization. The low-molecular-weight substances were removed by heating at $120^{\circ} \mathrm{C}$ in vacuo for $2 \mathrm{~h}$ to afford $48.2 \mathrm{~g}$ of H-ODMS. Yield: $84.6 \%$.

${ }^{1} \mathrm{H}$ NMR $\delta\left(400 \mathrm{MHz}, \mathrm{CDCl}_{3}, \mathrm{ppm}\right): 0.07((6 \mathrm{~m}+9)-$ $\mathrm{H}, \mathrm{bs}), 4.70(1 \mathrm{H}, \mathrm{m})$.

The average degree of polymerization $(\mathrm{m})=17.2$

Other H-ODMS with different degree of polymerization $(\mathrm{m}=14.2)$ was prepared according to the same procedure as above by using four equivalent amount of $\mathrm{D}_{3}$ against trimethylsilanol.

\section{Synthesis of 4-Chloromethylphenyl-terminated ODMS (CMP-ODMS)}

H-ODMS $(\mathrm{m}=17.2,20.0 \mathrm{~g}, 16.8 \mathrm{mmol})$ and 4chloromethylstyrene $(2.14 \mathrm{~g}, 14 \mathrm{mmol})$ were mixed under an argon atmosphere. To this solution, $15 \mathrm{~mL}$ of dry toluene and $0.03 \mathrm{~mL}$ of $1.0 \mathrm{M}$ 2-propanol solution of chloroplatinic acid were added, and the mixture was stirred at $80^{\circ} \mathrm{C}$ for $6 \mathrm{~h}$. After heating at $120^{\circ} \mathrm{C}$ in vacuo for $2 \mathrm{~h}$, the product was purified by column chromatography on silica gel with hexane to afford $12.5 \mathrm{~g}$ of CMP-ODMS. Yield: $66.3 \%$.

${ }^{1} \mathrm{H}$ NMR $\delta\left(400 \mathrm{MHz}, \mathrm{CDCl}_{3}, \mathrm{ppm}\right): 0.07$ (b), 0.90 (m), $1.36(\mathrm{~d}, J=10 \mathrm{~Hz}), 2.63(\mathrm{~m}), 4.56(\mathrm{~b}), 7.08$ (m), 7.19 (m), 7.28 (b), 7.30 (m). $\alpha$-adduct/ $\beta$-adduct $=30 / 70(\mathrm{~mol} \%)$.

The average degree of polymerization $(\mathrm{m})=19.1$

Other CMP-ODMS with different degree of polymerization $(\mathrm{m}=13.0)$ was prepared according to the same procedure as above by using H-ODMS $(\mathrm{m}=14.2)$.

Synthesis of 4,4'-bis(4-Carboxylphthalimido)diphenylmethane (1)

Under an argon atmosphere, trimellitic anhydride $(7.25 \mathrm{~g}, 37.6 \mathrm{mmol})$ and 4,4'-diaminodiphenylmethane $(3.00 \mathrm{~g}, 15.1 \mathrm{mmol})$ was dissolved in $100 \mathrm{~mL}$ of NMP, and the solution was stirred at room temperature for overnight. Then, $14.4 \mathrm{~mL}$ of triethylamine and 9.2 $\mathrm{mL}$ of acetic anhydride were added to this solution, and the temperature was raised to $100^{\circ} \mathrm{C}$ with continuous stirring. After it was stirred at $100^{\circ} \mathrm{C}$ for overnight, this solution was poured into an excess amount of water to obtain the crude product by filtration. The product was washed with hot ethanol to obtain $6.13 \mathrm{~g}$ of 1. Yield: $74.3 \%$.

${ }^{1} \mathrm{H}$ NMR $\delta\left(400 \mathrm{MHz}\right.$, DMSO- $\left.d_{6}, \mathrm{ppm}\right): 4.10(2 \mathrm{H}, \mathrm{s})$, $7.43\left(8 \mathrm{H}, \mathrm{dd}, J_{\mathrm{a}}=8.43 \mathrm{~Hz}, J_{\mathrm{b}}=11.7 \mathrm{~Hz}\right), 8.05(2 \mathrm{H}$, $\mathrm{d}, J=7.74 \mathrm{~Hz}), 8.31(2 \mathrm{H}, \mathrm{s}), 8.41(2 \mathrm{H}, \mathrm{d}, J=7.75$ $\mathrm{Hz}), 13.7$ (2H, bs).

\section{Synthesis of Poly(amide-imide) (PAI)}

The obtained monomer compound 1 (13.0 g, 23.8 mmol) and 4,4'-diaminodiphenylmethane $(4.72 \mathrm{~g}$, $23.8 \mathrm{mmol}$ ) were dissolved in $86 \mathrm{~mL}$ of NMP, and $52 \mathrm{~mL}$ of triphenyl phosphite and $32 \mathrm{~mL}$ of pyridine were added to this solution. After the mixture was stirred at $100^{\circ} \mathrm{C}$ for overnight, it was poured into excess amount of methanol, to obtain $13.1 \mathrm{~g}$ of PAI. Yield: $77.9 \%$.

${ }^{1} \mathrm{H}$ NMR: see Figure 1.

\section{Synthesis of PAI/ODMS Graft Copolymer}

Sodium hydride $(60 \% \mathrm{NaH}$ in oil, $113 \mathrm{mg}$, $2.82 \mathrm{mmol}$ ) was dispersed in $4 \mathrm{~mL}$ of dry DMSO, and the mixture was stirred at $70^{\circ} \mathrm{C}$ for $2 \mathrm{~h}$. To this solution, PAI $(1.00 \mathrm{~g}, 1.41 \mathrm{mmol})$ and $4.0 \mathrm{~mL}$ of dry DMSO was added, and the mixture was stirred at $100^{\circ} \mathrm{C}$ for overnight. Then, after CMP-ODMS $(\mathrm{m}=19.1,4.63 \mathrm{~g}, 2.82 \mathrm{mmol})$ and $5 \mathrm{~mL}$ of pyridine were added to this mixture, it was stirred at $100^{\circ} \mathrm{C}$ for another overnight. Finally, the reaction mixture was poured into an excess amount of methanol to precipitate the polymer. By this polymer reaction, $2.33 \mathrm{~g}$ of PAI/ODMS graft copolymer was obtained.

${ }^{1} \mathrm{H}$ NMR: see Figure 1.

Substitution ratio: $84.6 \%$ /amide group of PAI.

Other graft copolymers with different ODMS content were prepared according to the similar procedure 


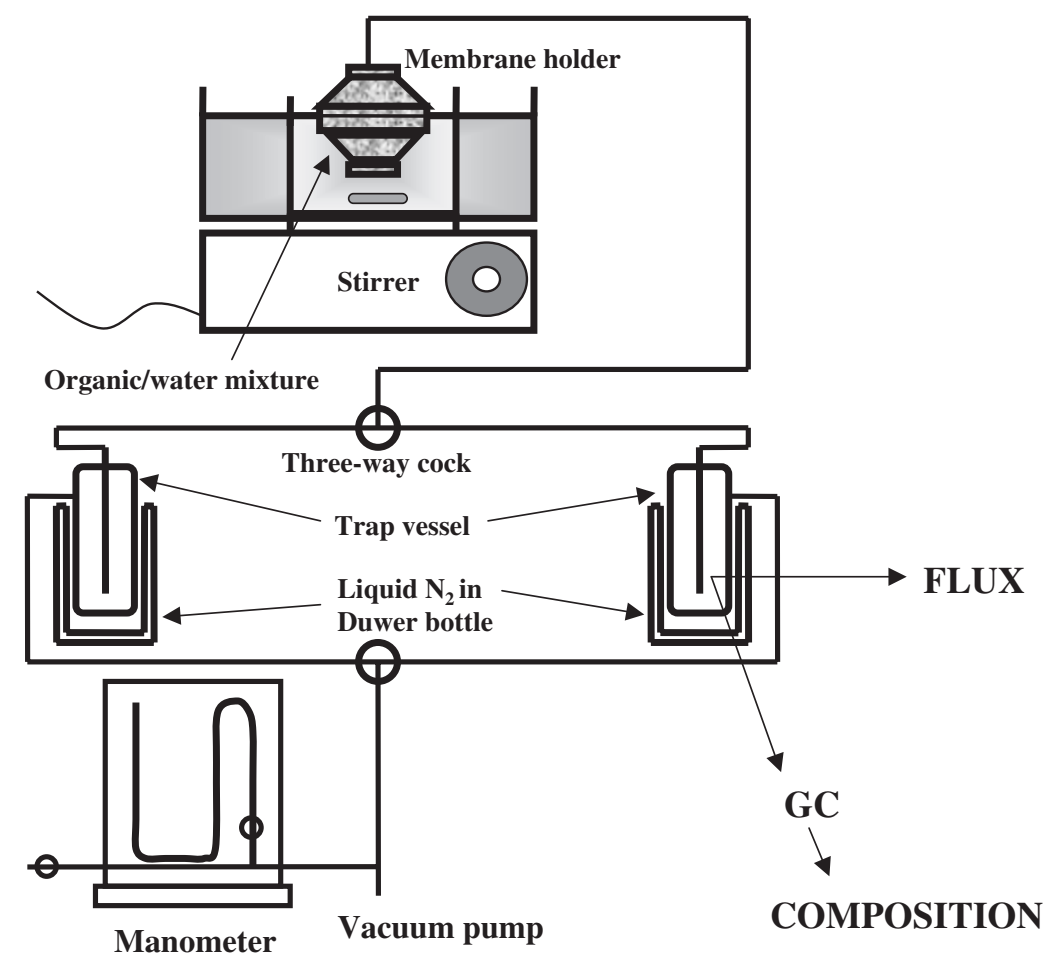

Figure 1. Apparatus for PV measurement.

by changing degree of polymerization (m) of CMPODMS or mole ratio of $\mathrm{NaH}$ in the above reaction.

\section{Characterizations}

${ }^{1} \mathrm{H}$ NMR was conducted by using a JEOL NMTH5SK FT-NMR $(400 \mathrm{MHz})$ spectrometer. Gel permeation chromatography (GPC) was carried out to determine the number-average $\left(M_{\mathrm{n}}\right)$ and weight-average $\left(M_{\mathrm{w}}\right)$ molecular weights with a Tosoh HLC-802A instrument by using THF as eluent, equipped with four columns of TSK gels $\mathrm{G} 5000 \mathrm{H}_{6}, \mathrm{G} 4000 \mathrm{H}_{6}, \mathrm{G} 3000 \mathrm{H}_{6}$ and $\mathrm{G}_{2} 000 \mathrm{H}_{6}$. Standard polystyrenes were used to calibrate the molecular weights.

\section{Membrane Preparation}

One gram of PAI/ODMS graft copolymers were dissolved in $5-10 \mathrm{~mL}$ of NMP. The solutions were cast on a polytetrafluoroethylene sheets, and the solvent was evaporated at $100^{\circ} \mathrm{C}$ over a period of $24 \mathrm{~h}$ to form membranes of $100-200 \mu \mathrm{m}$ thickness. Then, the obtained membranes were heated at $80^{\circ} \mathrm{C}$ in $v a$ cuo for $3 \mathrm{~h}$.

\section{Pervaporation Experiment}

The sample membrane for the measurement of pervaporation was cut into circular pieces with a diameter of $40 \mathrm{~mm}$. Pervaporation of aqueous organic liquid solutions through the membrane was carried out by the ordinary method using a stainless steel cell, which was dipped in a feed solution kept at $40^{\circ} \mathrm{C}$. The appa- ratus for the pervaporation experiment is schematically illustrated in Figure 1. The permeation area of the membrane was $9.6 \mathrm{~cm}^{2}$, and the pressure in the downstream side was kept at $1.0-2.0 \mathrm{mmHg}$. Ethanol, acetone, THF and dichloromethane were selected as the organic liquids. The permeated vapor was trapped in a vessel cooled with liquid $\mathrm{N}_{2}$, and the concentration of permeate was determined by gas chromatography (Apparatus: Shimadzu GC-14B, Column: Thermon1000 5\% Sunpack-A, Carrier gas: He). In the case of the permeation of aqueous dichloromethane solution, the permeate was diluted with THF before the GC measurement to make the mixture homogeneous.

The flux $\left(J, \mathrm{~kg} \mathrm{~m}^{-2} \mathrm{~h}^{-1}\right)$ and the permeability coefficient $\left(P, \mathrm{~kg} \mathrm{~m} \mathrm{~m}^{-2} \mathrm{~h}^{-1}\right)$ were calculated from the weight of permeate $(w)$ in the vessel, the permeation time $(t)$, the membrane thickness $(L)$ and the permeation area $(A)$, according to the equations shown below;

$$
\begin{aligned}
& J=w / A t \\
& P=w L / A t
\end{aligned}
$$

The separation factor, $\alpha$, was defined as the equation below;

$$
\alpha=\left(X_{\text {organic }} / X_{\text {water }}\right) /\left(Y_{\text {organic }} / Y_{\text {water }}\right)
$$

where $X_{\text {organic }}$ is the mass fraction of organic liquid in permeate, $X_{\text {water }}$ is the mass fraction of water in permeate, $Y_{\text {organic }}$ is the mass fraction of organic liquid in feed, and $Y_{\text {water }}$ is the mass fraction of water in feed. 

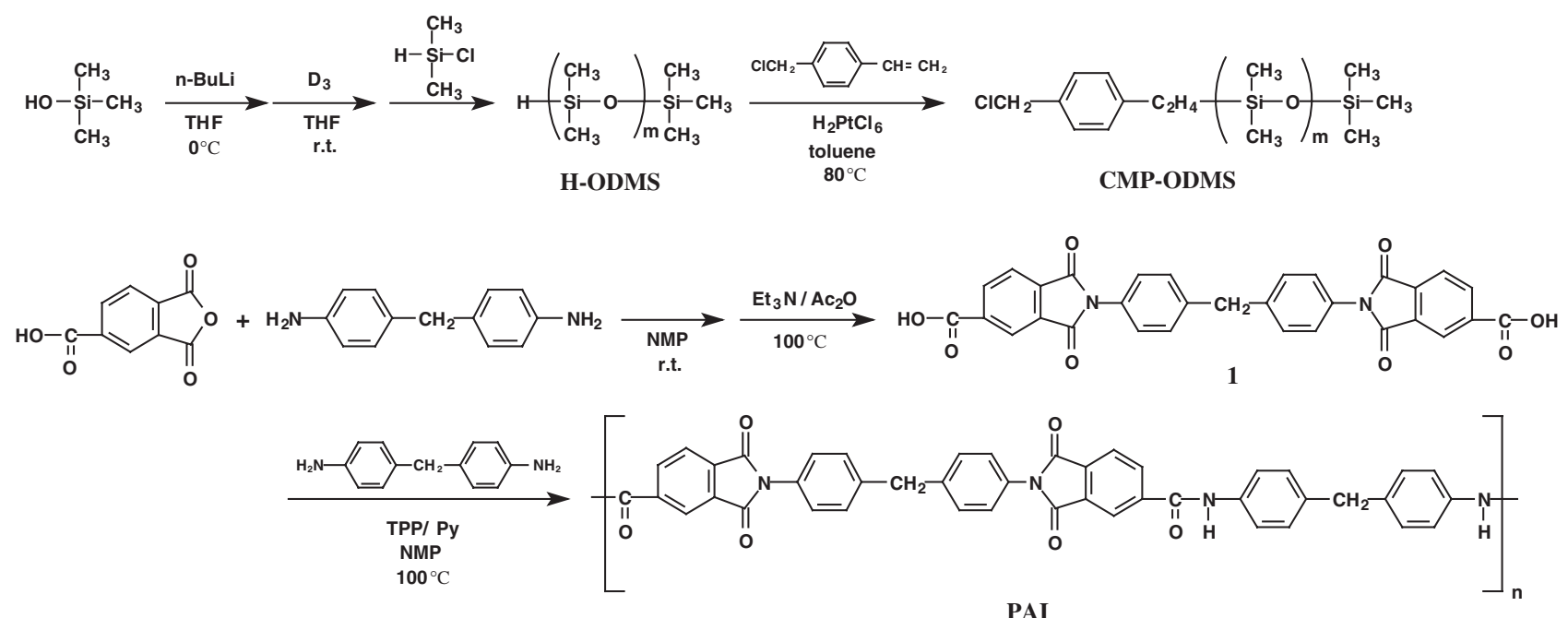

Scheme 1. Preparation of reactive ODMS (CMP-ODMS) and poly(amide-imide) homopolymer (PAI).

\section{RESULTS AND DISCUSSION}

\section{Preparation of PAI/ODMS Graft Copolymers}

For the reactive ODMS compound used in the oligomer-polymer reaction, chloromethylphenyl-terminated ODMS (CMP-ODMS) was prepared as shown in Scheme 1. The starting H-ODMS was prepared by non-equilibrium ring-opening polymerization of hexamethylcyclotrisiloxane $\left(\mathrm{D}_{3}\right)$ initiated with trimethylsilanolate anion, which was derived from trimethylsilanol with an equivalent amount of $n$-butyllithium, followed by terminating the reaction with dimethylchlorosilane. The average degree of polymerization, $m$, could be controlled by changing the ratio of $\mathrm{D}_{3}$ and trimethylsilanol in the polymerization. Then, the desired CMP-ODMS was prepared by hydrosilylation of H-ODMS with 4-chloromethylstyrene in the presence of chloroplatinic acid as catalyst. Two isomers were identified in the hydrosilylation product, one of which was the $\alpha$-adduct of the siloxane moiety to the vinyl group of 4-chloromethylstyrene and the other was the $\beta$-adduct. The mole ratio of $\alpha / \beta$ adducts was about $3 / 7$, which was determined by ${ }^{1} \mathrm{H}$ NMR spectra. Two kinds of CMP-ODMSs with different molecular weights were prepared as summarized in Table I.
As a backbone polymer, poly(amide-imide) (PAI) containing diphenylmethane and phthalimide moieties was prepared by a direct polycondensation of $4,4^{\prime}-$ bis(4-carboxylphthalimido)diphenylmethane (1) and 4,4'-diaminodiphenylmethane as shown in Scheme 1. The monomer compound, $\mathbf{1}$, was easily prepared by the reaction of trimellitic anhydride with 4,4'-diaminodiphenylmethane, followed by a chemical imidation with triethylamine and acetic anhydride. The obtained PAI was soluble in NMP and DMSO, but partially soluble in DMF, and insoluble in methanol, ethanol, acetone, THF, chloroform, dichloromethane and benzene. The solubility of PAI would be suitable for the PV membrane material which possesses both the processability for the preparation of thin membrane and the durability against the permeating organic components. However, the molecular weight of PAI could not be measured by GPC because of its poor solubility in THF and DMF.

Poly(amide-imide)/oligodimethylsiloxane (PAI/ ODMS) graft copolymer was prepared by substitution reaction between CMP-ODMS and polyanion of PAI, which was derived from the reaction of PAI with sodium hydride in DMSO. The reaction scheme and the results of polymer reaction are shown in Scheme 2 and Table II, respectively. In this polymer reaction,

Table I. Results of preparations of the reactive oligodimethylsiloxane (CMP-ODMS)

\begin{tabular}{|c|c|c|c|c|c|c|}
\hline \multirow{2}{*}{ Run } & \multirow{2}{*}{$\mathrm{D}_{3} / \mathrm{TMSOH}^{\mathrm{a}}$} & \multicolumn{2}{|c|}{$\mathrm{m}^{\mathrm{b}}$ of H-ODMS } & \multirow{2}{*}{$\begin{array}{c}\mathrm{m}^{\mathrm{c}} \text { of } \\
\text { CMP-ODMS }\end{array}$} & \multirow{2}{*}{$\begin{array}{c}M_{\mathrm{n}}{ }^{\mathrm{d}} \text { of } \\
\text { CMP-ODMS }\end{array}$} & \multirow{2}{*}{$\begin{array}{l}M_{\mathrm{w}} / M_{\mathrm{n}}{ }^{\mathrm{d}} \text { of } \\
\text { CMP-ODMS }\end{array}$} \\
\hline & & Theo. & Obs. & & & \\
\hline 1 & 4.0 & 13.0 & 14.2 & 13.2 & $3.09 \times 10^{3}$ & 1.16 \\
\hline 2 & 5.0 & 16.0 & 17.2 & 19.1 & $3.85 \times 10^{3}$ & 1.15 \\
\hline
\end{tabular}

${ }^{\mathrm{a}}$ Mole ratio of $\mathrm{D}_{3}$ and trimethylsilanol (TMSOH) in the preparation of H-ODMS. ${ }^{\mathrm{b}}$ Average degree of polymerization $(\mathrm{m})$ of H-ODMS. The theoretical value of $\mathrm{m}$ was calculated from the equation, $\mathrm{m}=$ $3\left[\mathrm{D}_{3}\right] /[\mathrm{TMSOH}]$, and the observed value was estimated on the basis of ${ }^{1} \mathrm{H}$ NMR spectrum. ${ }^{\mathrm{c}}$ Average degree of polymerization (m) of CMP-ODMS, determined by ${ }^{1} \mathrm{H}$ NMR spectrum. ${ }^{\mathrm{d}}$ Number-average and weight-average molecular weight $\left(M_{\mathrm{n}}\right.$ and $\left.M_{\mathrm{w}}\right)$ were determined by GPC. 


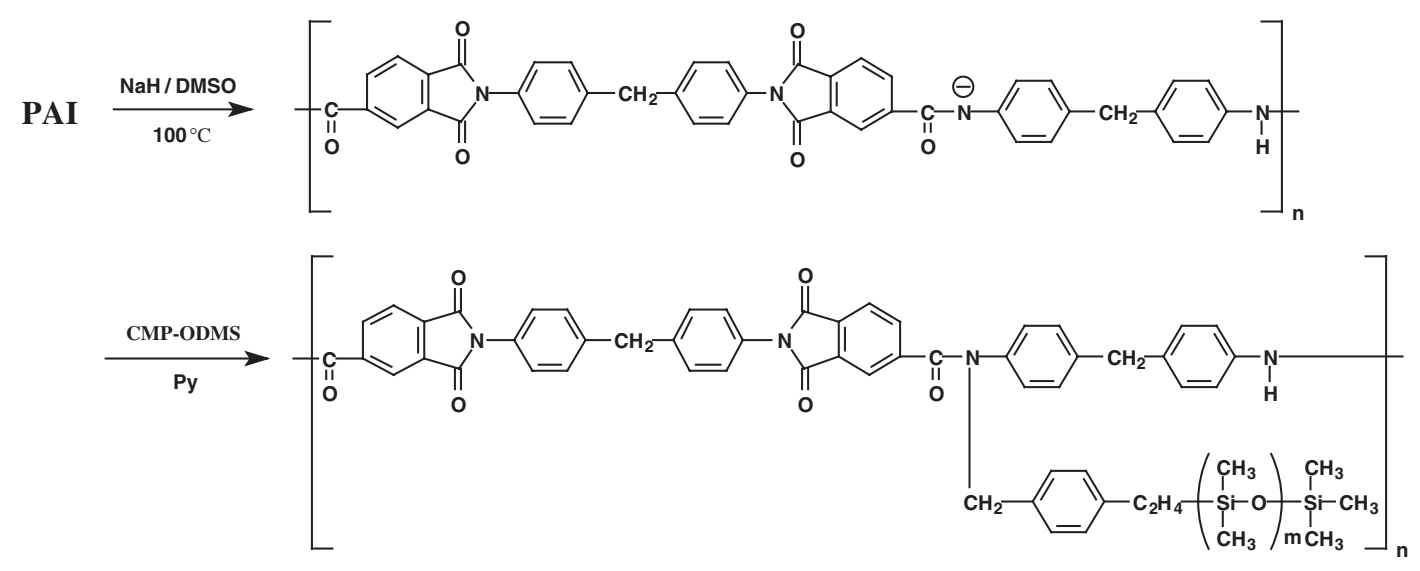

PAI/ODMS graft copolymer

Scheme 2. Preparation of PAI/ODMS graft copolymer by polymer reaction of PAI and CMP-ODMS.

Table II. Results of oligomer-polymer reaction between PAI and CMP-ODMS

\begin{tabular}{cccccc}
\hline Code & $\begin{array}{c}\mathrm{m}^{\mathrm{a}} \text { of } \\
\text { CMP-ODMS }\end{array}$ & $\begin{array}{c}{[\mathrm{NaH}] /[\mathrm{amide}]^{\mathrm{b}}} \\
(\mathrm{mol} \%)\end{array}$ & $\begin{array}{c}\text { Substitution ratio }^{\mathrm{c}} \\
(\mathrm{mol} \%)\end{array}$ & $\begin{array}{c}\text { PAI/ODMS }^{\mathrm{d}} \\
(\text { mole ratio) }\end{array}$ & $\begin{array}{c}\text { ODMS content }^{\mathrm{e}} \\
(\text { wt \%) }\end{array}$ \\
\hline PAI/ODMS-1 & 13.0 & 50 & 31.1 & $20 / 80$ & 29.5 \\
PAI/ODMS-2 & 13.0 & 100 & 47.0 & $15 / 85$ & 37.2 \\
PAI/ODMS-3 & 19.1 & 50 & 19.1 & $22 / 78$ & 27.1 \\
PAI/ODMS-4 & 19.1 & 100 & 84.6 & $6 / 94$ & 62.1 \\
\hline
\end{tabular}

${ }^{a}$ Average degree of polymerization (m) of CMP-ODMS, determined by ${ }^{1} \mathrm{H}$ NMR spectra. ${ }^{b}$ Mole ratio of NaH against the amide unit of PAI in the polymer reaction. ${ }^{\mathrm{c}}$ Substitution ratio of ODMS chain at N-position of amide group (see Scheme 2), determined by ${ }^{1} \mathrm{H}$ NMR spectra. ${ }^{\mathrm{d}}$ Mole ratio of PAI and ODMS monomer units in the graft copolymer. ${ }^{\text {e}}$ The content of ODMS component in the graft copolymer.

the addition of pyridine with CMP-ODMS was effective to improve the substitution ratio of ODMS segment in the copolymer. Probably, the compatibility of PAI polyanion and CMP-ODMS would be increased by the presence of pyridine to make the substitution smoothly in the reaction mixture. According to such a polymer reaction, the ODMS segment was substituted on the N-position of amide group to afford the desired graft copolymer.

The substitution ratio of ODMS segment in the obtained graft copolymers was determined by ${ }^{1} \mathrm{H}$ NMR spectra as illustrated in Figure 2, which was calculated from the ratio of the peak intensities of methylene protons of PAI unit and methyl protons of ODMS unit. As shown in Table II, the mole ratio of $\mathrm{NaH}$ against the amide unit in PAI was changed in a half and an equivalent amount each, which resulted in the different substitution ratio of ODMS segment on the N-position of PAI backbone. However, the substitution ratio could not be controlled precisely by this oligomer-polymer reaction, where PAI/ODMS graft copolymers containing several siloxane contents with two different lengths of ODMS segment were obtained. The reaction condition of this polymer reaction should be optimized to control the substitution ratio more precisely.
The obtained PAI/ODMS graft copolymers were soluble in aprotic polar solvents such as NMP and DMSO, but insoluble in methanol, ethanol, acetone, THF, chloroform, dichloromethane and benzene, the solubility of which was similar to that of PAI homopolymer. Therefore, the solubility and the processability of the graft copolymers were improved as compared with that of siloxane-grafted polyimide, ${ }^{7,10}$ but the durability against the separating organic components was maintained by the property of the backbone component.

\section{Pervaporation Results of PAI/ODMS Graft Copoly- mer Membranes}

The graft copolymer membranes were prepared by a solvent-casting method from their NMP solutions, and the tough and elastic membranes were obtained. Then, the separation characteristics of organic liquids/water mixtures with a low concentration of organic liquids were evaluated by PV experiments for the three kinds of graft copolymer membranes of PAI/ODMS-1, 3 and 4, which contain the different ODMS contents and segment lengths as listed in Table II. The results of PV experiments were summarized in Table III.

For all the membranes, the organic permselectivity 

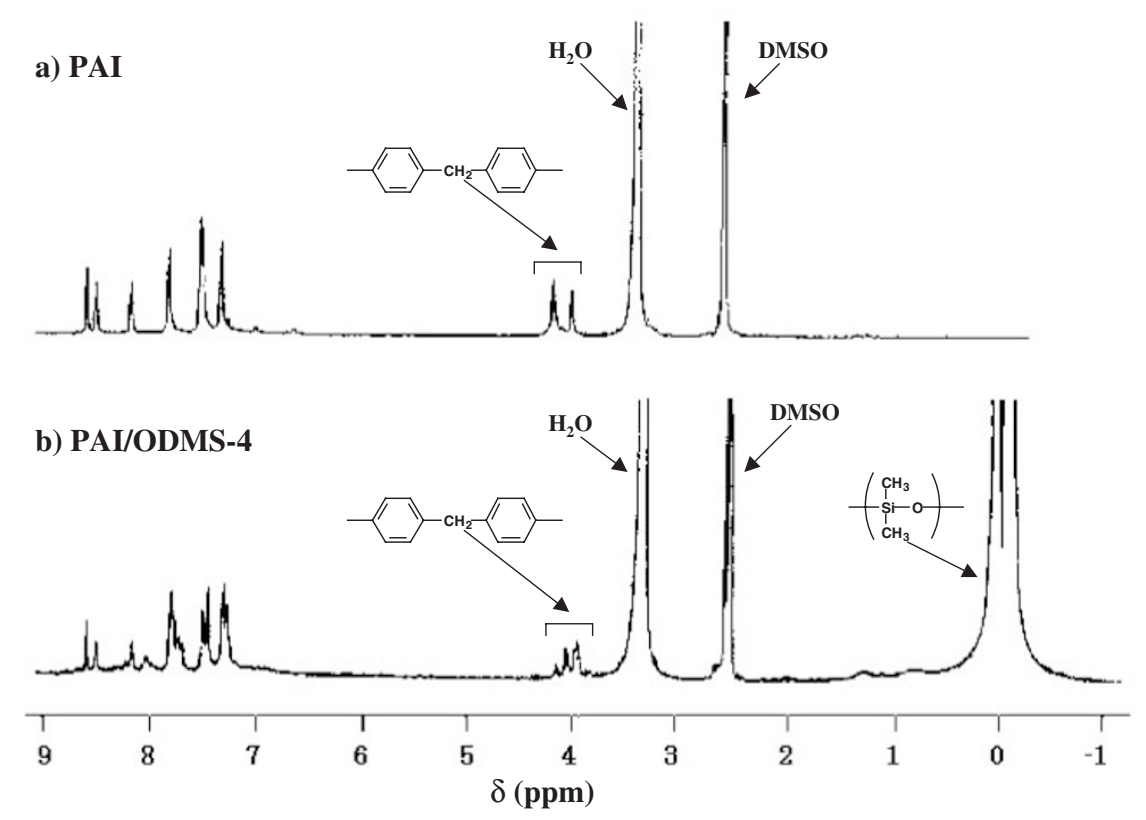

Figure 2. ${ }^{1} \mathrm{H}$ NMR spectra of PAI and PAI/ODMS graft copolymer (PAI/ODMS-4) in DMSO- $d_{6}$.

Table III. Results of pervaporation of aqueous organic liquid solutions through PAI/ODMS graft copolymer membranes at $40^{\circ} \mathrm{C}$, as compared with PI/ODMS membrane

\begin{tabular}{|c|c|c|c|c|c|c|}
\hline \multirow{2}{*}{ Code } & \multirow{2}{*}{ Organic liquid } & \multicolumn{2}{|c|}{ Composition $^{\mathrm{a}}$ (wt \%) } & \multirow{2}{*}{$\alpha \begin{array}{c}\text { Org. }^{\mathrm{b}} \\
\text { Water }\end{array}$} & \multirow{2}{*}{$\begin{array}{c}J^{\mathrm{b}} \\
\left(\mathrm{kg} \mathrm{m}^{-2} \mathrm{~h}^{-1}\right)\end{array}$} & \multirow{2}{*}{$\begin{array}{c}P^{\mathrm{b}} \\
\left(\mathrm{kg} \mathrm{m} \mathrm{m}^{-2} \mathrm{~h}^{-1}\right)\end{array}$} \\
\hline & & in feed & in permeate & & & \\
\hline \multirow[t]{2}{*}{ PAI/ODMS-1 } & Ethanol & 8.56 & 13.6 & 1.68 & 0.024 & $3.50 \times 10^{-6}$ \\
\hline & Acetone & 9.86 & 84.5 & 50.4 & 0.156 & $2.25 \times 10^{-5}$ \\
\hline \multirow[t]{2}{*}{ PAI/ODMS-3 } & Ethanol & 8.20 & 11.1 & 1.40 & 0.024 & $2.76 \times 10^{-6}$ \\
\hline & Acetone & 8.80 & 28.9 & 4.21 & 0.031 & $3.55 \times 10^{-6}$ \\
\hline \multirow[t]{4}{*}{ PAI/ODMS-4 } & Ethanol & 4.60 & 34.0 & 10.7 & 0.080 & $1.51 \times 10^{-5}$ \\
\hline & Acetone & 6.61 & 83.1 & 69.5 & 0.145 & $2.74 \times 10^{-5}$ \\
\hline & Tetrahydrofuran & 8.00 & 86.0 & 70.6 & 0.415 & $7.84 \times 10^{-5}$ \\
\hline & Dichloromethane & 0.80 & 72.9 & 334 & 0.991 & $1.87 \times 10^{-4}$ \\
\hline \multirow[t]{3}{*}{$\mathrm{PI} / \mathrm{ODMS}^{\mathrm{c}}$} & Acetone & 11.5 & 81.4 & 34.2 & 0.491 & $9.60 \times 10^{-5}$ \\
\hline & Tetrahydrofuran & 6.90 & 94.2 & 251 & 0.922 & $2.06 \times 10^{-4}$ \\
\hline & Dichloromethane & 0.90 & 71.3 & 274 & 0.331 & $7.40 \times 10^{-5}$ \\
\hline
\end{tabular}

${ }^{\mathrm{a}}$ Composition of organic liquid in feed and permeate. ${ }^{\mathrm{b}} \alpha$ : Separation factor, $J$ : Flux, $P$ : Permeability coefficient. ${ }^{c} \mathrm{PV}$ results of polyimide/oligodimethylsiloxane graft copolymer membrane, according to ref 10 .

was observed in PV of dilute aqueous solutions of ethanol and acetone. In the cases of PAI/ODMS-1 and 3 membranes, ODMS contents of which were almost same but the segment lengths were different, the selectivity for ethanol was similarly low. Probably, the ODMS contents of the both PAI/ODMS graft copolymers were not enough to exhibit the high selectivity for ethanol percolation. Uragami et al. revealed that the continuity of the ODMS phase in the microphase separation strongly influenced the ethanol permselectivity of block and graft copolymers containing ODMS segment, and the percolation transition of the ODMS phase took place at a ODMS content of about $35 \mathrm{~mol} \%(28 \mathrm{wt} \%)$ in ODMS-grafted poly(methyl methacrylate) membrane. ${ }^{11}$ The ODMS con- tents of PAI/ODMS-1 and 3, which were 29.5 and $27.1 \mathrm{wt} \%$, respectively, would cause a boundary morphological effect to exhibit the ethanol permselectivity. On the contrary, PAI/ODMS-1 membrane exhibited unexpectedly the higher selectivity for aqueous acetone permeation than PAI/ODMS-3 membrane. From these results, it was considered that the ODMS segment length and the degree of substitution of ODMS chain would affect the membrane permeability in such kinds of ODMS grafted copolymer membranes. Actually, the hydrophobicity of the membrane surfaces of PAI/ODMS-1 and 3 was found to be different by the measurements of contact angle of water. The values of contact angles of water on the surfaces of PAI/ODMS- 1 and 3 membranes were $107^{\circ}$ and 
$59^{\circ}$, respectively, therefore, PAI/ODMS-1 possessed the more hydrophobic surface than PAI/ODMS-3. It would be due to the higher degree of substitution of ODMS chain in PAI/ODMS-1, where the membrane surface was covered with ODMS component even the ODMS contents of the two copolymers were similar. In addition, the higher diffusivity of acetone than ethanol would cause the higher selective permeation of acetone through PAI/ODMS-1 membrane.

On the other hand, for PAI/ODMS-4 membrane, the high selective permeations of organic liquids were observed in pervaporation of dilute aqueous solutions of ethanol, acetone, THF and dichloromethane, as shown in Table III. These results suggested that the continuous ODMS phase was formed in PAI/ ODMS-4 membrane because of its high degree of substitution of long ODMS segments. Furthermore, the stable permeation was observed even in the permeations of the aqueous solutions containing THF and dichloromethane. It would be due to the durability of the backbone component, PAI, against these organic solvents. In addition, the separation property of PAI/ ODMS-4 membrane was almost same as that of ODMS-grafted polyimide membrane ${ }^{10}$ which was insoluble in any solvent, as shown in Table III.

Consequently, it would be possible that this kind of membrane material can be used for the removal of organic components from wastewater, since it exhibits the good processability to produce a thin membrane, the high organic-permselectivity in the pervaporation and the durability to separating organic components. However, it was also found that the ODMS content of PAI/ODMS graft copolymer was difficult to control by such a oligomer-polymer reaction, although the
ODMS content played an important role to achieve the high selectivity in the pervaporation of aqueous organic liquids mixture. Then, the improved synthetic pathway to prepare a similar PAI/ODMS graft copolymer is now in progress via a macromonomer method using a diamino-terminated ODMS oligomer.

Acknowledgment. This study was supported by the grant of the Mukai Science Technology Foundation, Japan. We express our sincere gratitude to the foundation.

\section{REFERENCES}

1. S. Takegami, H. Yamada, and S. Tsujii, J. Membrane Chem., 75, 93 (1992).

2. K. Okamoto, A. Butsuen, S. Tsuru, S. Nishioka, K. Tanaka, H. Kita, and S. Asakawa, Polym. J., 19, 747 (1987).

3. T. Miyata, S. Obata, and T. Uragami, Macromolecules, 32, 8465 (1999).

4. Y. Nagase, S. Mori, K. Matsui, and M. Uchikura, J. Polym. Sci., Polym. Chem. Ed., 26, 3131 (1988).

5. Y. Nagase, A. Naruse, and K. Matsui, Polymer, 31, 121 (1990).

6. Y. Nagase, K. Ishihara, and K. Matsui, J. Polym. Sci., Polym. Phys. Ed., 28, 377 (1990).

7. Y. Nagase, S. Mori, M. Egawa, and K. Matsui, Makromol. Chem., 191, 2413 (1990).

8. E. Akiyama, Y. Takamura, and Y. Nagase, Makromol. Chem., 193, 1509 (1992).

9. E. Akiyama, Y. Takamura, and Y. Nagase, Makromol. Chem., 193, 2037 (1992).

10. Y. Nagase, J. Kimura, M. Akimoto, H. Yamazaki, and A. Kinoshita, Trans. Mater. Res. Soc. Jpn., 26, 1315 (2001).

11. T. Miyata, S. Obata, and T. Uragami, Macromolecules, 32, 3712 (1999). 